\title{
A Fuzzy Multicriteria Group Decision-Making Method with New Entropy of Interval-Valued Intuitionistic Fuzzy Sets
}

\author{
Xiaohong Chen, Li Yang, Pei Wang, and Wei Yue \\ Business School, Central South University, Changsha 410083, China \\ Correspondence should be addressed to Li Yang; yangli@csu.edu.cn \\ Received 14 September 2012; Accepted 30 March 2013 \\ Academic Editor: Farhad Hosseinzadeh Lotfi
}

Copyright (c) 2013 Xiaohong Chen et al. This is an open access article distributed under the Creative Commons Attribution License, which permits unrestricted use, distribution, and reproduction in any medium, provided the original work is properly cited.

\begin{abstract}
A new entropy measure of interval-valued intuitionistic fuzzy set (IVIFS) is proposed by using cotangent function, which overcomes several limitations in the existing methods for calculating entropy of IVIFS. The efficiency of the new entropy is demonstrated by comparing it with several classical entropies. Moreover, an entropy weight model is established to determine the entropy weights for fuzzy multicriteria group decision-making (FMCGDMs) problems, which depends on incomplete weight information of criteria in IVIFSs setting. Finally, an illustrative supplier selection problem is used to demonstrate the practicality and effectiveness of the proposed method. It is capable of the handling the FMCGDM problems with incomplete known weights for criteria.
\end{abstract}

\section{Introduction}

The theory of fuzzy sets (FSs) proposed by Zadeh [1] has achieved a great success in various fields. A lot of generalized forms of FSs have been proposed. The classical sets include interval-valued fuzzy sets (IVFSs) [2], intuitionistic fuzzy sets (IFSs) [3, 4], interval-valued intuitionistic fuzzy sets (IVIFSs) [5], R-fuzzy sets [6], and intuitionistic linguistic fuzzy sets (ILFSs) [7]. From [4, 8-10], it turns out that IVFS theory is equivalent to IFS theory, and IVIFS theory extends IFS theory.

As an important topic in the theory of fuzzy sets, entropy measures of IFSs have been investigated widely by many researchers from different views. Burillo and Bustince [11] introduced the notion that entropy of IVFSs and IFSs can be used to evaluate the degree of intuitionism of an IVFS or IFS. Szmidt and Kacprzyk [12] proposed a nonprobabilistictype entropy measure with a geometric interpretation of IFSs. Hung and Yang [13] gave their axiomatic definitions of entropy of IFSs and IVFSs by using the concept of probability. Wei et al. [14] gave a new entropy measure for IVIFSs to overcome the disadvantages of those three entropy measures defined independently by Szmidt and Kacprzyk [12], Wang and Lei [15], and Huang and Liu [16]. Different entropy formulas for IFS $[15,17]$, IVFS $[18,19]$, and vague set $[16,20$, 21] were also proposed by other researchers.
The entropy of IFSs has been applied widely in decision making $[22,23]$. On the one hand, due to the increasing complexity of the social-economic environment and a lack of information about the problem domains, the decision information may be provided with IVIFSs, whose membership degree and nonmembership degree are intervals, instead of real numbers. Entropy is concerned as a measure of fuzziness. Therefore, it is highly necessary and significant to study the entropy of IVIFSs. And on the other hand, a proper assessment of attribute weights plays an essential role in the MADM process [24]. In terms of determining weights, the entropy method is one of the most representative approaches, which expresses the relative intensities of attribute importance to signify the average intrinsic information transmitted to the DM $[22,25,26]$. The following are some of the research findings.

Ye [27] proposed two entropy measures for IVIFSs and established an entropy weight model, which could be used to determine the criteria weights on alternatives. Zhang et al. [28] proposed a new information entropy measure of IVIFS by using membership interval and nonmembership interval of IVIFSs, which complied with the extended form of De Luca and Termini [29] axioms for fuzzy entropy. Wei et al. [14] also proposed an entropy measure for IVIFSs, and they applied the new entropy measure to solve problem on multicriteria fuzzy decision making. 
However, the entropy is seldom applied in multiexpert and multicriteria decision making, which is one of the most important branches of decision-making method. Due to limited investigation on multiexpert and multicriteria decision-making issues, this study proposed a novel formula to calculate the entropy of an IVIFS on the basis of the argument on the relationship among the entropies of IFSs given in $[27,30]$. For interval-valued intuitionistic fuzzy multicriteria group decision-making problem, in which the information on the weights of criteria is incomplete, a linear fuzzy programming model based on intuitionistic fuzzy entropy is constructed to obtain the criteria weights.

The rest of this paper is organized as follows. In Section 2, we introduce some basic notions of IFS and IVIFSs. In Section 3, we propose a new entropy measure of intervalvalued intuitionistic fuzzy set by using cotangent function. In Section 4, the method and procedure for solving FMCGDM problems with the new entropy measure of interval-valued intuitionistic fuzzy set are developed in detail. An illustrative supplier selection problem was employed to demonstrate how to apply the proposed approach in Section 5. Short conclusion is given in Section 6.

\section{Interval-Valued Intuitionistic Fuzzy Sets}

Definition 1 (see [3]). Let $X$ be an ordinary finite nonempty set. An intuitionistic fuzzy set (IFS) in $X$ is an object of the form:

$$
A=\left\{\left\langle x, \mu_{A}(x), v_{A}(x)\right\rangle \mid x \in X\right\}
$$

where

$$
\mu_{A}: X \longrightarrow[0,1], \quad v_{A}: X \longrightarrow[0,1]
$$

with the condition $0 \leq \mu_{A}(x)+\nu_{A}(x) \leq 1$, for all $x \in X$.

The numbers $\mu_{A}(x), v_{A}(x)$ denote the degree of membership and nonmembership of the element $x$ in the set $A$, respectively.

For each IFS, we call $\pi_{A}(x)=1-\mu_{A}(x)-v_{A}(x)$ the intuitionistic index of the element $x$ in the set $A$. It also denotes the hesitancy degree of $x$ to $A$.

Definition 2 (see [5]). Let $D[0,1]$ be the set of all closed subintervals of the interval $[0,1]$, and let $X$ be an ordinary finite nonempty set. An interval-valued intuitionistic fuzzy set (IVIFS) in $X$ is an object of the form:

$$
A=\left\{\left\langle x, \tilde{\mu}_{A}(x), \tilde{v}_{A}(x)\right\rangle \mid x \in X\right\}
$$

$x$ in the set $A$, where $\tilde{\mu}_{A}: X \rightarrow D[0,1], \widetilde{\nu}_{A}: X \rightarrow D[0,1]$, with the condition $0 \leq \sup \left(\widetilde{\mu}_{A}(x)\right)+\sup \left(\widetilde{\nu}_{A}(x)\right) \leq 1$, for all $x \in X$.

The intervals $\tilde{\mu}_{A}(x), \widetilde{v}_{A}(x)$ denote the degree of membership and nonmembership of the element $x$ in the set $A$, respectively.
For convenience, let $\tilde{\mu}_{A}(x)=\left[\mu_{A L}(x), \mu_{A U}(x)\right], \widetilde{v}_{A}(x)=$ $\left[v_{A L}(x), v_{A U}(x)\right]$, then

$$
A=\left\{\left\langle x,\left[\mu_{A L}(x), \mu_{A U}(x)\right],\left[v_{A L}(x), v_{A U}(x)\right]\right\rangle \mid x \in X\right\},
$$

where $0 \leq \mu_{A U}(x)+v_{A U}(x) \leq 1, \mu_{A L}(x) \geq 0$, and $v_{A L}(x) \geq 0$.

For each element $x$, we can compute the intuitionistic index of an intuitionistic fuzzy interval of $x \in X$ in $A$ defined as follows:

$$
\begin{aligned}
\tilde{\pi}_{A}(x) & =1-\tilde{\mu}_{A}(x)-\widetilde{v}_{A}(x) \\
& =\left[1-\mu_{A U}(x)-v_{A U}(x), 1-\mu_{A L}(x)-v_{A L}(x)\right] .
\end{aligned}
$$

For convenience, an IVIFS value is denoted by $A=([a, b]$, $[c, d])$.

Definition 3 (see [5]). Assume $A, B \in \operatorname{IVIFS}(X)$, then some operations can be defined as follows:

$$
\begin{array}{r}
A \cup B=\left\{\left\langlex_{i},\left[\mu_{A L}\left(x_{i}\right) \vee \mu_{B L}\left(x_{i}\right), \mu_{A U}\left(x_{i}\right) \vee \mu_{B U}\left(x_{i}\right)\right],\right.\right. \\
\left.\left.\left[v_{A L}\left(x_{i}\right) \wedge v_{B L}\left(x_{i}\right), v_{A U}\left(x_{i}\right) \wedge v_{B U}\left(x_{i}\right)\right]\right\rangle\right\}, \\
A \cap B=\left\{\left\langlex_{i},\left[\mu_{A L}\left(x_{i}\right) \wedge \mu_{B L}\left(x_{i}\right), \mu_{A U}\left(x_{i}\right) \wedge \mu_{B U}\left(x_{i}\right)\right],\right.\right. \\
\left.\left.\left[v_{A L}\left(x_{i}\right) \vee v_{B L}\left(x_{i}\right), v_{A U}\left(x_{i}\right) \vee v_{B U}\left(x_{i}\right)\right]\right\rangle\right\} .
\end{array}
$$

The following expressions are defined in [5] for all $A, B \in$ $\operatorname{IVFSs}(X)$ :

$A \subseteq B$ if and only if $\mu_{A L} \leq \mu_{B L}, \mu_{A U} \leq \mu_{B U}, v_{A L} \geq v_{B L}$, and $v_{A U} \geq v_{B U}$ for all $x \in X$;

$A=B$ if and only if $A \subseteq B$ and $B \subseteq A$ for all $x \in X$;

$A^{C}=\left\{\left\langle x,\left[v_{A L}(x), v_{A U}(x)\right],\left[\mu_{A L}(x), \mu_{A U}(x)\right]\right\rangle \mid x \in\right.$ $X\}$.

In the following, we introduce two weighted aggregation operators related to IVIFSs.

Definition 4 (see [31]). Let $A_{j}(j=1,2, \ldots, n) \in \operatorname{IVIFS}(X)$. The weighted geometric average operator (IVIF-WGA operator) is defined by

$$
\begin{aligned}
& F_{w}\left(A_{1}, A_{2}, \ldots, A_{n}\right) \\
&=\left(\left[\prod_{j=1}^{n} \mu_{A_{j} L}(x)^{w_{j}}, \prod_{j=1}^{n} \mu_{A_{j} U}(x)^{w_{j}}\right],\right. \\
& {\left.\left[1-\prod_{j=1}^{n}\left(1-v_{A_{j} L}(x)\right)^{w_{j}}, 1-\prod_{j=1}^{n}\left(1-v_{A_{j} U}(x)\right)^{w_{j}}\right]\right), }
\end{aligned}
$$

where $w_{j}$ is the weight of $A_{j}(j=1,2, \ldots, n), w_{j} \in[0,1]$ and $\sum_{j=1}^{n} w_{j}=1$. Particularly, if $w_{j}=1 / n(j=1,2, \ldots, n)$, then $F_{w}$ is called a geometric average operator for IVIFSs. 
Definition 5 (see [31]). Let $A_{j}(j=1,2, \ldots, n) \in \operatorname{IVIFS}(X)$. The hybrid averaging operator (IVIF-HA operator) is defined by

$$
\begin{aligned}
& H_{w}\left(A_{1}, A_{2}, \ldots, A_{n}\right) \\
&=\left(\left[\prod_{j=1}^{n} \mu_{B_{j} L}(x)^{w_{j}}, \prod_{j=1}^{n} \mu_{B_{j} U}(x)^{w_{j}}\right],\right. \\
& {\left.\left[1-\prod_{j=1}^{n}\left(1-v_{B_{j} L}(x)\right)^{w_{j}}, 1-\prod_{j=1}^{n}\left(1-v_{B_{j} U}(x)\right)^{w_{j}}\right]\right), }
\end{aligned}
$$

where $w_{j}$ is the weight of $B_{j}(j=1,2, \ldots, n), w_{j} \in[0,1]$ and $\sum_{j=1}^{n} w_{j}=1 . B_{j}$ is the $j$ th largest one of all values $\left(n \omega_{1} A_{1}, n \omega_{2} A_{2}, \ldots, n \omega_{n} A_{n}\right)$, and $\omega_{k}$ is the weight of $A_{k}(k=$ $1,2, \ldots, n)$, satisfying $\omega_{k} \in[0,1]$ and $\sum_{k=1}^{n} \omega_{k}=1 . n$ is a balance factor. Here, $W=\left(w_{1}, w_{2}, \ldots, w_{n}\right)^{T}$ can be obtained by the following formula:

$$
w_{j}=Q\left(\frac{j}{l}\right)-Q\left(\frac{(j-1)}{l}\right), \quad j=1,2, \ldots, n,
$$

where

$$
Q= \begin{cases}0, & r<a, \\ \frac{r-a}{a-b}, & a \leq r \leq b, \\ 1, & r>b .\end{cases}
$$

We utilize the principle of antonym pairs most, at least half, as many as possible, where the parameters $(a, b)$ are equal to $(0.3,0.8),(0,05)$, and $(0.5,1)$, respectively.

Definition 6 (see [32]). Let $A=([a, b],[c, d])$ be an intervalvalued intuitionistic fuzzy number. A score function $S$ of an interval-valued intuitionistic fuzzy value can be represented as follows:

$$
S(A)=\frac{a-c+b-d}{2} .
$$

Definition 7 (see [32]). Let $A_{1}=\left(\left[a_{1}, b_{1}\right],\left[c_{1}, d_{1}\right]\right)$ and $A_{2}=$ $\left(\left[a_{2}, b_{2}\right],\left[c_{2}, d_{2}\right]\right)$ be two interval-valued intuitionistic fuzzy values, and let $S\left(A_{1}\right)=\left(a_{1}-c_{1}+b_{1}-d_{1}\right) / 2$ and $S\left(A_{2}\right)=$ $\left(a_{2}-c_{2}+b_{2}-d_{2}\right) / 2$ be the scores of $A_{1}$ and $A_{2}$, respectively, then if $S\left(A_{1}\right)<S\left(A_{2}\right), A_{1}$ is smaller than $A_{2}$, denoted by $A_{1}<A_{2}$.

\section{Interval-Valued Intuitionistic Fuzzy Entropy}

Definition 8 (see [23]). A real-valued function $E$ : $\operatorname{IVIFS}(X)$ $\rightarrow \quad[0,1]$ is called an entropy measure on $\operatorname{IVIFS}(X)$ if it satisfies the following axiomatic requirements:

(P1) $E(A)=0$, if and only if $A$ is a crisp set;

(P2) $E(A)=1$, if and only if $\tilde{\mu}_{A}\left(x_{i}\right)=\widetilde{v}_{A}\left(x_{i}\right)$ for all $x_{i} \in X$;
(P3) $E(A)=E\left(A^{C}\right)$ for all $x_{i} \in \operatorname{IVIFS}(X)$;

(P4) $E(A) \leq E(B)$ if $A$ is less fuzzy than $B$; that is, $\mu_{A L}\left(x_{i}\right) \leq$ $v_{A L}\left(x_{i}\right), \mu_{A U}\left(x_{i}\right) \leq v_{A U}\left(x_{i}\right)$, and $A \subseteq B$ for all $x_{i} \in X$ or $\mu_{A L}\left(x_{i}\right) \geq v_{A L}\left(x_{i}\right), \mu_{A U}\left(x_{i}\right) \geq v_{A U}\left(x_{i}\right)$, and $B \subseteq A$ for all $x_{i} \in X$.

3.1. The Limitations of the Existing Interval-Valued Intuitionistic Fuzzy Entropy. Let us suppose that $E\left(A_{i}\right)$ is the entropy of IVIFSs.

Vlachos' entropy measure [30] is as follows

$E^{1}(A)$

$$
=1-\sqrt{\frac{1}{2 n} \sum_{i=1}^{n}\left(\left|\mu_{A L}\left(x_{i}\right)-v_{A L}\left(x_{i}\right)\right|\right)^{2}+\left(\left|\mu_{A U}\left(x_{i}\right)-v_{A U}\left(x_{i}\right)\right|\right)^{2}} .
$$

Example 9. Let $A=([0.4,0.5],[0.3,0.4])$ and $B=([0.1,0.2]$, $[0,0.1])$ be two IVIFSs in $X$.

Intuitively, we can see that $B$ is more fuzzy than $A$. If we calculate the $E^{1}(A)$ and $E^{1}(B)$ by (12), then we can obtain

$$
\begin{aligned}
& E^{1}(A)=1-\sqrt{\frac{1}{2}\left(|0.4-0.3|^{2}+|0.5-0.4|^{2}\right)}=0.9 \\
& E^{1}(B)=1-\sqrt{\frac{1}{2}\left(|0.1-0|^{2}+|0.2-0.1|^{2}\right)}=0.9
\end{aligned}
$$

which indicate that $E^{1}(A)=E^{1}(B)$ and is not consistent with our intuition.

Ye's entropy measures [27] are as follows

$E^{2}(A)$

$=\left\{\sin \frac{\pi \times\left[1+\mu_{A L}\left(x_{i}\right)+p W_{\mu A}\left(x_{i}\right)-v_{A L}\left(x_{i}\right)-q W_{v A}\left(x_{i}\right)\right]}{4}\right.$
$\left.+\sin \frac{\pi \times\left[1-\mu_{A L}\left(x_{i}\right)-p W_{\mu A}\left(x_{i}\right)+v_{A L}\left(x_{i}\right)+q W_{\nu A}\left(x_{i}\right)\right]}{4}-1\right\}$

$\times \frac{1}{\sqrt{2}-1}$

where $p, q \in[0,1]$ are two fixed numbers, $W_{\mu A}(x)=\mu_{A U}(x)-$ $\mu_{A L}(x)$, and $W_{v A}(x)=v_{A U}(x)-v_{A L}(x)$.

Example 10. Let $A=([0.5,0.5],[0.1,0.1])$ and $B=([0.6,0.6]$, $[0.2,0.2])$ be two IVIFSs in $X$. 
Intuitively, $A$ is more fuzzy than $B$. Now the $E^{2}(A)$ and $E^{2}(B)$ can be gained by (14) and take $p=q=0.5$, and the results are

$$
\begin{aligned}
E^{2}(A)= & \left\{\sin \frac{\pi \times[1+0.5-0.1]}{4}\right. \\
& \left.+\sin \frac{\pi \times[1-0.5+0.1]}{4}-1\right\} \\
& \times \frac{1}{\sqrt{2}-1}=0.833, \\
E^{2}(B)= & \left\{\sin \frac{\pi \times[1+0.6-0.2]}{4}\right. \\
& \left.+\sin \frac{\pi \times[1-0.6+0.2]}{4}-1\right\} \\
& \times \frac{1}{\sqrt{2}-1}=0.833,
\end{aligned}
$$

which indicate that $E^{2}(A)=E^{2}(B)$ and are not consistent with our intuition.

\subsection{New Interval-Valued Intuitionistic Fuzzy Entropy Based} on Cotangent Function. A new interval-valued intuitionistic fuzzy entropy measure is introduced as follows.

Definition 11. Assuming that $A \in \operatorname{IVIFS}(X)$, then an intervalvalued intuitionistic fuzzy entropy measure can be defined as

$$
\begin{gathered}
E(A) \\
\begin{array}{c}
n \sum_{i=1}^{n} \cot \left(\frac{1}{4} \pi+\left(\frac{1}{2} \mid \mu_{A L}\left(x_{i}\right)-v_{A L}\left(x_{i}\right)\right.\right. \\
\left.+\mu_{A U}\left(x_{i}\right)-v_{A U}\left(x_{i}\right) \mid\right) \\
\left.\times\left(4\left(1+\pi_{A}\left(x_{i}\right)\right)\right)^{-1} \pi\right) \\
=\frac{1}{n} \sum_{i=1}^{n} \cot \left(\frac{1}{4} \pi+\left(\mid \mu_{A L}\left(x_{i}\right)-v_{A L}\left(x_{i}\right)\right.\right. \\
\left.+\mu_{A U}\left(x_{i}\right)-v_{A U}\left(x_{i}\right) \mid\right) \\
\times\left(4 \left(4-\mu_{A L}\left(x_{i}\right)-v_{A L}\left(x_{i}\right)\right.\right. \\
\left.\left.\left.-\mu_{A U}\left(x_{i}\right)-v_{A U}\left(x_{i}\right)\right)^{-1}\right) \pi\right) .
\end{array}
\end{gathered}
$$

Theorem 12. The mapping $E(A)$, defined by (16), is an entropy measure for IVIFSs.

Proof. In order for (16) to be qualified as a sensible measure of interval-valued intuitionistic fuzzy entropy, it must satisfy the conditions (P1)-(P4) in Definition 8.

Let $0 \leq \tilde{\mu}_{A}\left(x_{i}\right), \widetilde{v}_{A}\left(x_{i}\right)$, and $\tilde{\pi}_{A}\left(x_{i}\right) \leq 1$; we have $0 \leq$ $\left|\mu_{A L}\left(x_{i}\right)-v_{A L}\left(x_{i}\right)+\mu_{A U}\left(x_{i}\right)-v_{A U}\left(x_{i}\right)\right| \leq 2$. It follows that $\left(0 \leq\left|\mu_{A L}\left(x_{i}\right)-v_{A L}\left(x_{i}\right)+\mu_{A U}\left(x_{i}\right)-v_{A U}\left(x_{i}\right)\right| / 8\left(1+\pi_{A}\left(x_{i}\right)\right)\right) \pi \leq$ $(1 / 4) \pi$. Thus $0 \leq E(A) \leq 1$.
(P1) Let $A$ be a crisp set. Then we have $\tilde{\pi}_{A}\left(x_{i}\right)=0, \tilde{\mu}_{A}\left(x_{i}\right)=$ 1 , and $\widetilde{v}_{A}\left(x_{i}\right)=0$ or $\tilde{\pi}_{A}\left(x_{i}\right)=0, \tilde{\mu}_{A}\left(x_{i}\right)=0$, and $\widetilde{v}_{A}\left(x_{i}\right)=1$. So $E(A)=0$.

(P2) Let $\widetilde{\mu}_{A}\left(x_{i}\right)=\widetilde{v}_{B}\left(x_{i}\right)$, then $E(A)=1$.

(P3) It is clear that $A^{C}=\left\{\left\langle x_{i},\left[v_{A L}\left(x_{i}\right), v_{A U}\left(x_{i}\right)\right],\left[\mu_{A L}\left(x_{i}\right)\right.\right.\right.$, $\left.\left.\left.\mu_{A U}\left(x_{i}\right)\right]\right\rangle \mid x_{i} \in X\right\}$. By applying (11), we have $E(A)=$ $E\left(A^{C}\right)$.

(P4) In order to show that (11) fulfill the requirement of (P4), it is suffice to to prove the following function:

$$
\begin{aligned}
& \frac{\left|\mu_{A L}\left(x_{i}\right)-v_{A L}\left(x_{i}\right)+\mu_{A U}\left(x_{i}\right)-v_{A U}\left(x_{i}\right)\right|}{4\left(4-\mu_{A L}\left(x_{i}\right)-v_{A L}\left(x_{i}\right)-\mu_{A U}\left(x_{i}\right)-v_{A U}\left(x_{i}\right)\right)} \\
& \quad \geq \frac{\left|\mu_{B L}\left(x_{i}\right)-v_{B L}\left(x_{i}\right)+\mu_{B U}\left(x_{i}\right)-v_{B U}\left(x_{i}\right)\right|}{4\left(4-\mu_{B L}\left(x_{i}\right)-v_{B L}\left(x_{i}\right)-\mu_{B U}\left(x_{i}\right)-v_{B U}\left(x_{i}\right)\right)},
\end{aligned}
$$

where function $E$ is monotonic decreasing.

Suppose that $\mu_{B L}\left(x_{i}\right) \leq \nu_{B L}\left(x_{i}\right), \mu_{B U}\left(x_{i}\right) \leq \nu_{B U}\left(x_{i}\right)$, and $A \subseteq B$, in order to prove (17); namely, we prove that

$$
\begin{aligned}
& \left(2-\mu_{A L}\left(x_{i}\right)-\mu_{A U}\left(x_{i}\right)\right)\left(2-v_{B L}\left(x_{i}\right)-v_{B U}\left(x_{i}\right)\right) \\
& \quad \geq\left(2-\mu_{B L}\left(x_{i}\right)-\mu_{B U}\left(x_{i}\right)\right)\left(2-v_{A L}\left(x_{i}\right)-v_{A U}\left(x_{i}\right)\right) .
\end{aligned}
$$

If $\mu_{A L}\left(x_{i}\right) \leq \mu_{B L}\left(x_{i}\right)$ and $\mu_{A U}\left(x_{i}\right) \leq \mu_{B U}\left(x_{i}\right)$, then $2-\mu_{A L}\left(x_{i}\right)-$ $\mu_{A U}\left(x_{i}\right) \geq 2-\mu_{B L}\left(x_{i}\right)-\mu_{B U}\left(x_{i}\right) \geq 0$. If $v_{A L}\left(x_{i}\right) \geq v_{B L}\left(x_{i}\right)$ and $\mu_{A U}\left(x_{i}\right) \geq \mu_{B U}\left(x_{i}\right)$, then we have $2-v_{B L}\left(x_{i}\right)-v_{B U}\left(x_{i}\right) \geq 2-$ $v_{A L}\left(x_{i}\right)-v_{A U}\left(x_{i}\right) \geq 0$. So we can get that (18) holds. Therefore, $E(A) \leq E(B)$.

Similarly, when $\mu_{B L}\left(x_{i}\right) \geq v_{B L}\left(x_{i}\right), \mu_{B U}\left(x_{i}\right) \geq v_{B U}\left(x_{i}\right)$, and $B \subseteq A$, we can also prove that $E(A) \leq E(B)$.

Example 13. Let $A=([0.4,0.5],[0.3,0.4])$ and $B=([0.1,0.2]$, $[0,0.1])$ be two IVIFSs in $X$.

Intuitively, we can see that $B$ is more fuzzy than $A$. Now we calculate the $E(A)$ and $E(B)$ by (16), and we can obtain that

$$
\begin{aligned}
& E(A)=\cot \left(\frac{1}{4} \pi+\frac{|0.4-0.3+0.5-0.4|}{4(4-0.4-0.3-0.5-0.4)} \pi\right)=0.877, \\
& E(B)=\cot \left(\frac{1}{4} \pi+\frac{|0.1-0+0.2-0.1|}{4(4-0.1-0-0.2-0.1)} \pi\right)=0.916
\end{aligned}
$$

which indicate that $E(A)<E(B)$ and are consistent with our intuition.

Example 14. Let $A=([0.5,0.5],[0.1,0.1])$ and $B=([0.6,0.6]$, $[0.2,0.2])$ be two IVIFSs in $X$.

Intuitively, we can see that $A$ is more fuzzy than $B$. Now we calculate the $E(A)$ and $E(B)$ by (16), and we can obtain that

$$
\begin{aligned}
& E(A)=\cot \left(\frac{1}{4} \pi+\frac{|0.5-0.1+0.5-0.1|}{4(4-0.5-0.1-0.5-0.1)} \pi\right)=0.628, \\
& E(B)=\cot \left(\frac{1}{4} \pi+\frac{|0.6-0.2+0.6-0.2|}{4(4-0.6-0.2-0.6-0.2)} \pi\right)=0.577,
\end{aligned}
$$

which indicate that $E(A)>E(B)$ and are consistent with our intuition. 


\section{Fuzzy Multicriteria Group Decision-Making Method Based on the New Interval-Valued Intuitionistic Fuzzy Entropy}

In this section, we propose a method for fuzzy group decision-making problems based on the interval-valued intuitionistic fuzzy entropy.

Consider an interval-valued intuitionistic fuzzy multicriteria group decision-making problem. Assume that there are $n$ alternatives $X=\left\{x_{1}, x_{2}, \ldots, x_{n}\right\}$ and $m$ decision criteria $C=\left\{c_{1}, c_{2}, \ldots, c_{m}\right\}$ with weight vector $W=\left(w_{1}, w_{2}, \ldots, w_{m}\right)^{T}$ associated with $C$, where $w_{j} \in[0,1]$ and $\sum_{j=1}^{m} w_{j}=1$. Assume that there are $t$ decision makers $D=\left\{d_{1}, d_{2}, \ldots, d_{t}\right\}$ whose corresponding weight vector is $\lambda=\left(\lambda_{1}, \lambda_{2}, \ldots, \lambda_{t}\right)^{T}$, where $\lambda_{k} \in[0,1]$ and $\sum_{k=1}^{t} \lambda_{k}=1$. In this case, the characteristic of the alternative $A_{i}$ of the $k$ th decision maker $d_{k}$ is represented by the following IVIFS:

$$
\begin{aligned}
A_{i}^{k}=\{ & \left\{C_{j}^{k},\left[\mu_{A_{i}^{k} L}\left(C_{j}^{k}\right), \mu_{A_{i}^{k} U}\left(C_{j}^{k}\right)\right],\right. \\
& {\left.\left.\left[v_{A_{i}^{k} L}\left(C_{j}^{k}\right), v_{A_{i}^{k} U}\left(C_{j}^{k}\right)\right]\right\rangle \mid C_{j}^{k} \in C\right\}, }
\end{aligned}
$$

where $0 \leq \mu_{A_{i}^{k} U}\left(C_{j}^{k}\right)+v_{A_{i}^{k} U}\left(C_{j}^{k}\right) \leq 1, \mu_{A_{i}^{k} L}\left(C_{j}^{k}\right) \geq 0, \mu_{A_{i}^{k} L}\left(C_{j}^{k}\right) \geq$ $0, i=1,2, \ldots, n, j=1,2, \ldots, m$, and $k=1,2, \ldots, t$. The IVIFS value that is the pair of intervals $\mu_{A_{i}^{k}}\left(C_{j}^{k}\right)=$ $\left[a_{i j}^{k}, b_{i j}^{k}\right], v_{A_{i}^{k}}\left(C_{j}^{k}\right)=\left[c_{i j}^{k}, d_{i j}^{k}\right]$ for $C_{j}^{k} \in C$ is denoted by $r_{i j}^{k}=\left(\left[a_{i j}^{k}, b_{i j}^{k}\right],\left[c_{i j}^{k}, d_{i j}^{k}\right]\right)$. Here, we can elicit the interval-valued intuitionistic fuzzy decision matrix $R^{k}=\left(r_{i j}^{k}\right)_{n \times m}$.

If the information about weight $w_{j}$ of the criterion $C_{j}(j=1,2, \ldots, m)$ is incomplete, for determining the criterion weight from the decision matrix we can establish a model of interval-valued intuitionistic fuzzy entropy weights.

For the criteria $C_{j}$, the entropy of the alternative $A_{i}$ of the $k$ th decision maker can be given as

$$
\begin{gathered}
E\left(r_{i j}^{k}\right) \\
=\cot \left(\frac{1}{4} \pi+\left(\left|\mu_{A L}\left(r_{i j}^{k}\right)-v_{A L}\left(r_{i j}^{k}\right)+\mu_{A U}\left(r_{i j}^{k}\right)-v_{A U}\left(r_{i j}^{k}\right)\right|\right)\right. \\
\times\left(4 \left(4-\mu_{A L}\left(r_{i j}^{k}\right)-v_{A L}\left(r_{i j}^{k}\right)\right.\right. \\
\left.\left.\left.-\mu_{A U}\left(r_{i j}^{k}\right)-v_{A U}\left(r_{i j}^{k}\right)\right)\right)^{-1} \pi\right) .
\end{gathered}
$$

And the entropy for the alternative $A_{i}^{k}$ of the $k$ th decision maker is given as

$$
\begin{aligned}
& E\left(A_{i}^{k}\right) \\
& =\sum_{j=1}^{m} \cot \left(\frac{1}{4} \pi+\left(\mid \mu_{A L}\left(r_{i j}^{k}\right)-v_{A L}\left(r_{i j}^{k}\right)\right.\right. \\
& \left.+\mu_{A U}\left(r_{i j}^{k}\right)-v_{A U}\left(r_{i j}^{k}\right) \mid\right)
\end{aligned}
$$

$$
\begin{aligned}
\times(4(4 & -\mu_{A L}\left(r_{i j}^{k}\right)-v_{A L}\left(r_{i j}^{k}\right) \\
& \left.\left.\left.-\mu_{A U}\left(r_{i j}^{k}\right)-v_{A U}\left(r_{i j}^{k}\right)\right)\right)^{-1} \pi\right) .
\end{aligned}
$$

As each alternative is made in a fair competitive environment, and the fuzzy entropy of each alternative is from a same criteria weight coefficient, the alternatives should be combined. The overall entropy for the alternative $A_{i}$ is given as

$$
\begin{aligned}
& E\left(A_{i}\right) \\
& =\sum_{k=1}^{t} \sum_{j=1}^{m} \cot \left(\frac{1}{4} \pi+\left(\mid \mu_{A L}\left(r_{i j}^{k}\right)-v_{A L}\left(r_{i j}^{k}\right)\right.\right. \\
& \left.+\mu_{A U}\left(r_{i j}^{k}\right)-v_{A U}\left(r_{i j}^{k}\right) \mid\right) \\
& \times\left(4 \left(4-\mu_{A L}\left(r_{i j}^{k}\right)-v_{A L}\left(r_{i j}^{k}\right)\right.\right. \\
& \left.\left.\left.-\mu_{A U}\left(r_{i j}^{k}\right)-v_{A U}\left(r_{i j}^{k}\right)\right)\right)^{-1} \pi\right) .
\end{aligned}
$$

According to the entropy theory, if the entropy value for an alternative is smaller across alternatives, it can provide decision makers with the useful information. Therefore, the criteria should be assigned to a bigger weight value. Then the smaller the value of (24) is, the better the weight we should assign to the criteria.

Let $H$ be the set of incomplete information about criteria weights; to get the optimal weight vector, the following model can be constructed:

$\min E(A)$

$$
=\sum_{i=1}^{n} \sum_{k=1}^{t} \sum_{j=1}^{m} w_{j}
$$

$$
\begin{gathered}
\times \cot \left(\frac{1}{4} \pi+\left(\mid \mu_{A L}\left(r_{i j}^{k}\right)-v_{A L}\left(r_{i j}^{k}\right)\right.\right. \\
\left.+\mu_{A U}\left(r_{i j}^{k}\right)-v_{A U}\left(r_{i j}^{k}\right) \mid\right) \\
\times\left(4 \left(4-\mu_{A L}\left(r_{i j}^{k}\right)-v_{A L}\left(r_{i j}^{k}\right)\right.\right. \\
\left.\left.\left.-\mu_{A U}\left(r_{i j}^{k}\right)-v_{A U}\left(r_{i j}^{k}\right)\right)\right)^{-1} \pi\right),
\end{gathered}
$$

s.t. $\quad w \in H, \quad \sum_{j=1}^{m} w_{j}=1, \quad w_{j} \geq 0, j=1,2, \ldots, m$.

By solving model (25) with Lingo software, we get the optimal solution $\left(w_{1}, w_{2}, \ldots, w_{m}\right)^{T}$.

In summary, the main procedure of the decision method proposed is listed in the following.

Step 1. Calculate the weight vector $W=\left(w_{1}, w_{2}, \ldots, w_{m}\right)^{T}$ by solving model (25). 
Step 2. Aggregate the values of each decision maker, and utilize the IVIF-WGA operator to derive the values $z_{i}^{k}(i=$ $1,2, \ldots, n)$ of each decision maker as follows:

$$
z_{i}^{k}=F_{w}\left(r_{i 1}^{k}, r_{i 2}^{k}, \ldots, r_{i m}^{k}\right), \quad i=1,2, \ldots, n, k=1,2, \ldots, t .
$$

Step 3. Aggregate the values of all decision makers, and utilize the IVIF-HA operator to derive the collective values $z_{i}$ of the alternative $x_{i}$ as follows

$$
z_{i}=H_{\lambda}\left(z_{i}^{1}, z_{i}^{2}, \ldots, z_{i}^{t}\right), \quad i=1,2, \ldots, n,
$$

where the associated weighting vector $\lambda=\left(\lambda_{1}, \lambda_{2}, \ldots, \lambda_{t}\right)$ of the IVIF-HA operator.

Step 4. Calculate the scores $S\left(z_{i}\right)(i=1,2, \ldots, n)$ of the collective overall values to rank all the alternatives $A_{i}(i=$ $1,2, \ldots, n)$ and then to select the best one(s).

\section{An Illustration for Solving the Supplier Selection Problem}

This section adopts a supplier selection problem in $[33,34]$ to demonstrate how to apply the proposed approach. With continual business development, globalized markets become increasingly competitive. Establishing effective supply chain management (SCM) becomes a critical activity because a sound SCM system can reduce supply chain risk, maximize revenue, optimize business processes, and allow a company to maintain a dominant position in the market [34, 35]. On the other hand, it is a hard problem since supplier selection is typically a multicriteria group decision-making problem involving several conflicting criteria on which decision maker's knowledge is usually vague and imprecise [34]. Previous research concerning supplier selection often used exact numbers to measure criterion weights. In this study, considering that the decision maker may have difficulty in eliciting precise criterion weights, the proposed approach is proposed to select appropriate supplier in group decisionmaking environment. It should be noted that, as suggested and illustrated by Merigo and Gil-Lafuente [36], the proposed approach can be easily applied to a host of practical decision problems that involve choosing an optimal alternative from a list of alternatives when multiple attributes must be considered.

Suppose that a high-tech company which manufactures electronic products intends to evaluate and select a supplier of USB connectors. There are four suppliers $x_{1}, x_{2}, x_{3}$, and $x_{4}$ which are chosen as candidates. A committee of three decision makers $d_{1}, d_{2}$, and $d_{3}$ is established, which are an engineering expert, financial expert, and quality control expert, respectively. Four evaluated criteria are considered, including finance $\left(c_{1}\right)$, performance $\left(c_{2}\right)$, technique $\left(c_{3}\right)$, and organizational culture $\left(c_{4}\right)$. The expert weight vector is given by $\lambda=(0.35,0.35,0.3)^{T}$. The interval-valued intuitionistic fuzzy decision matrices of criterion values are constructed as follows:

$$
\begin{aligned}
R^{1}= & {\left[\begin{array}{llll}
([0.3,0.4],[0.4,0.6]) & ([0.6,0.7],[0.1,0.2]) & ([0.5,0.7],[0.2,0.3]) & ([0.7,0.8],[0.0,0.1]) \\
([0.7,0.8],[0.1,0.2]) & ([0.6,0.7],[0.2,0.3]) & ([0.2,0.3],[0.4,0.6]) & ([0.5,0.6],[0.1,0.3]) \\
([0.5,0.8],[0.1,0.2]) & ([0.7,0.8],[0.0,0.1]) & ([0.5,0.5],[0.4,0.5]) & ([0.2,0.3],[0.2,0.4]) \\
([0.2,0.3],[0.4,0.5]) & ([0.5,0.7],[0.1,0.3]) & ([0.6,0.7],[0.1,0.2]) & ([0.4,0.5],[0.1,0.3])
\end{array}\right], } \\
R^{2}= & \left.\begin{array}{llll}
([0.4,0.5],[0.3,0.4]) & ([0.5,0.6],[0.2,0.2]) & ([0.6,0.7],[0.2,0.3]) & ([0.7,0.8],[0.1,0.2]) \\
([0.6,0.8],[0.1,0.2]) & ([0.5,0.6],[0.3,0.4]) & ([0.4,0.5],[0.3,0.4]) & ([0.4,0.6],[0.3,0.4]) \\
([0.5,0.6],[0.3,0.4]) & ([0.5,0.7],[0.1,0.2]) & ([0.5,0.6],[0.3,0.4]) & ([0.3,0.4],[0.2,0.5]) \\
([0.5,0.6],[0.3,0.4]) & ([0.7,0.8],[0.0,0.1]) & ([0.4,0.5],[0.2,0.4]) & ([0.5,0.7],[0.1,0.2])
\end{array}\right], \\
R^{3}= & {\left[\begin{array}{llll}
([0.4,0.6],[0.3,0.4]) & ([0.5,0.7],[0.1,0.2]) & ([0.5,0.6],[0.2,0.4]) & ([0.6,0.8],[0.1,0.2]) \\
([0.5,0.8],[0.1,0.2]) & ([0.3,0.5],[0.2,0.3]) & ([0.3,0.6],[0.2,0.4]) & ([0.4,0.5],[0.2,0.4]) \\
([0.5,0.6],[0.0,0.1]) & ([0.5,0.8],[0.1,0.2]) & ([0.4,0.7],[0.2,0.3]) & ([0.2,0.4],[0.2,0.3]) \\
([0.5,0.7],[0.1,0.3]) & ([0.4,0.6],[0.0,0.1]) & ([0.3,0.5],[0.2,0.4]) & ([0.7,0.9],[0.0,0.1])
\end{array}\right] . }
\end{aligned}
$$

The incomplete information about the criterion weights are as follows (in this problem, the criterion weights are incomplete information. The specific weight calculation method can be found in [34]):

$$
\begin{aligned}
H=\{ & 0.228 \leq w_{1} \leq 0.8758,0.2285 \leq w_{2} \leq 0.8789, \\
& \left.0.1642 \leq w_{3} \leq 0.7979,0.1419 \leq w_{4} \leq 0.7824\right\}
\end{aligned}
$$

Step 1. Calculate the weight vector $W=\left(w_{1}, w_{2}, w_{3}, w_{4}\right)^{T}$ by solving model (25) as follows:

$$
W=(0.228,0.4659,0.1642,0.1419)^{T} .
$$

Step 2. Aggregate the values of each decision maker, andutilize the IVIF-WGA operator to derive the values $z_{i}^{k}(i=$ $1,2, \ldots, n)$ of each decision maker.

The integrated values for alternatives $x_{1}, x_{2}, x_{3}$ and $x_{4}$ of decision maker $d_{1}$ are, respectively,

$$
\begin{aligned}
z_{1}^{1} & =([0.508,0.628],[0.183,0.320]), \\
z_{2}^{1} & =([0.506,0.614],[0.203,0.342]), \\
z_{3}^{1} & =([0.514,0.644],[0.130,0.249]), \\
z_{4}^{1} & =([0.405,0.550],[0.179,0.337]) .
\end{aligned}
$$


The integrated values for alternatives $x_{1}, x_{2}, x_{3}$ and $x_{4}$ of decision maker $d_{2}$ are, respectively,

$$
\begin{aligned}
& z_{1}^{2}=([0.514,0.615],[0.211,0.267]), \\
& z_{2}^{2}=([0.487,0.622],[0.259,0.359]), \\
& z_{3}^{2}=([0.439,0.584],[0.198,0.331]), \\
& z_{4}^{2}=([0.546,0.649],[0.124,0.259]) .
\end{aligned}
$$

The integrated values for alternatives $x_{1}, x_{2}, x_{3}$ and $x_{4}$ of decision maker $d_{3}$ are, respectively,

$$
\begin{aligned}
z_{1}^{3} & =([0.488,0.672],[0.166,0.285]), \\
z_{2}^{3} & =([0.351,0.573],[0.178,0.312]), \\
z_{3}^{3} & =([0.423,0.664],[0.111,0.211]), \\
z_{4}^{3} & =([0.435,0.639],[0.06,0.205]) .
\end{aligned}
$$

Step 3. Aggregate the values of all decision makers, and utilize the IVIF-HA operator to derive the collective values $z_{i}$ of the alternative $x_{i}$.

The weighting vector of the IVIL-HA operator is obtained by the principle of antonym pairs many and $(a, b)$ equal to $(0.3,0.8)$. So we can obtain $\omega=(0.243,0.514,0.243)$ and the integrated values as follows:

$$
\begin{aligned}
& z_{1}=([0.489,0.617],[0.202,0.297]), \\
& z_{2}=([0.436,0.593],[0.236,0.357]), \\
& z_{3}=([0.430,0.625],[0.144,0.262]), \\
& z_{4}=([0.463,0.606],[0.129,0.278]) .
\end{aligned}
$$

Step 4. Calculate the scores $S\left(z_{i}\right)(i=1,2,3,4)$ of the collective overall values $z_{i}(i=1,2,3,4)$ as follows:

$$
\begin{array}{ll}
S\left(z_{1}\right)=0.607, & S\left(z_{2}\right)=0.436 \\
S\left(z_{3}\right)=0.649, & S\left(z_{4}\right)=0.663 .
\end{array}
$$

Step 5. Rank all the alternatives $A_{i}(i=1,2,3,4)$ in accordance with the score $S\left(z_{i}\right)$ of the collective overall interval-valued intuitionistic fuzzy values $z_{i}(i=1,2,3,4)$ : $A_{4}>A_{3}>A_{1}>A_{2}$, and thus the best alternative is $A_{4}$.

\section{Conclusion}

In this paper, a new entropy measure of IVIFS is proposed by using cotangent function, which can overcome limitations of some existing methods. And we provide several numerical examples to illustrate its validity. For interval-valued intuitionistic fuzzy multicriteria group decision-making problem with incomplete information on the weights of criteria, an entropy weight model is established to determine the entropy weights. In addition, the method and procedure are developed to solve FMCGDM problems. Finally, the supplier selection problem is used as an example to demonstrate how to apply the proposed multicriteria group decision-making approach.

\section{Acknowledgments}

The authors would like to thank Yufeng Xu, Fuqiang Wang, Mengjun Liao, Siying Wang, and the anonymous reviewers for their valuable comments on this paper. This paper was supported by the National Natural Science Foundation of China (no. 70921001).

\section{References}

[1] L. A. Zadeh, "Fuzzy sets," Information and Control, vol. 8, no. 3, pp. 338-356, 1965.

[2] L. A. Zadeh, "The concept of a linguistic variable and its application to approximate reasoning-I," Information Sciences, vol. 8, no. 3, pp. 199-249, 1975.

[3] K. T. Atanassov, "Intuitionistic fuzzy sets," Fuzzy Sets and Systems, vol. 20, no. 1, pp. 87-96, 1986.

[4] K. Atanassov, Intuitionistic Fuzzy Sets, Springer, Physica-Verlag, Heidelberg, Germany, 1999.

[5] K. Atanassov and G. Gargov, "Interval valued intuitionistic fuzzy sets," Fuzzy Sets and Systems, vol. 31, no. 3, pp. 343-349, 1989.

[6] Y. Yang and C. Hinde, "A new extension of fuzzy sets using rough sets: R-fuzzy sets," Information Sciences, vol. 180, no. 3, pp. 354-365, 2010.

[7] J. Q. Wang and H. B. Li, "Multi-criteria decision-making method based on aggregation operators for intuitionistic linguistic fuzzy numbers," Control and Decision, vol. 25, no. 10, pp. 1571-1584, 2010.

[8] H. Bustince and P. Burillo, "Vague sets are intuitionistic fuzzy sets," Fuzzy Sets and Systems, vol. 79, no. 3, pp. 403-405, 1996.

[9] C. Cornelis, K. T. Atanassov, and E. E. Kerre, "Intuitionistic fuzzy sets and interval-valued fuzzy sets: a critical comparison," in Proceedings of the 3rd European Conference on Fuzzy Logic and Technology (EUSFLAT '03), pp. 159-163, Zittau, Germany, 2003.

[10] G. Deschrijver and E. E. Kerre, "On the relationship between some extensions of fuzzy set theory," Fuzzy Sets and Systems, vol. 133, no. 2, pp. 227-235, 2003.

[11] P. Burillo and H. Bustince, "Entropy on intuitionistic fuzzy sets and on interval-valued fuzzy sets," Fuzzy Sets and Systems, vol. 78, no. 3, pp. 305-316, 1996.

[12] E. Szmidt and J. Kacprzyk, "Entropy for intuitionistic fuzzy sets," Fuzzy Sets and Systems, vol. 118, no. 3, pp. 467-477, 2001.

[13] W. L. Hung and M. S. Yang, "Fuzzy entropy on intuitionistic fuzzy sets," International Journal of Intelligent Systems, vol. 21, no. 4, pp. 443-451, 2006.

[14] C.-P. Wei, P. Wang, and Y. Z. Zhang, "Entropy, similarity measure of interval-valued intuitionistic fuzzy sets and their applications," Information Sciences, vol. 181, no. 19, pp. 42734286, 2011.

[15] Y. Wang and Y. J. Lei, "A technique for constructing intuitionistic fuzzy entropy," Control and Decision, vol. 22, no. 12, pp. 13901394, 2007.

[16] G. S. Huang and Y. S. Liu, "The fuzzy entropy of vague sets based on non-fuzzy sets," Computer Applications and Software, vol. 22, no. 6, pp. 16-17, 2005.

[17] I. K. Vlochos and G. D. Sergiadis, "Intuitionistic fuzzy information-applications to pattern recognition," Pattern Recognition Letter, vol. 28, no. 2, pp. 197-206, 2007. 
[18] W. Zeng and H. Li, "Relationship between similarity measure and entropy of interval valued fuzzy sets," Fuzzy Sets and Systems, vol. 157, no. 11, pp. 1477-1484, 2006.

[19] H. Zhang, W. Zhang, and C. Mei, "Entropy of interval-valued fuzzy sets based on distance and its relationship with similarity measure," Knowledge-Based Systems, vol. 22, no. 6, pp. 449-454, 2009.

[20] G. S. Huang and Y. S. Liu, "On the fuzzy entropy of vague sets," Computer Engineering and Applications, vol. 41, no. 33, pp. 4850, 2005.

[21] Q. S. Zhang and S. Y. Jiang, "A note on information entropy measures for vague sets and its applications," Information Sciences, vol. 178, no. 21, pp. 4184-4191, 2008.

[22] T. Y. Chen and C. H. Li, "Determining objective weights with intuitionistic fuzzy entropy measures: a comparative analysis," Information Sciences, vol. 180, no. 21, pp. 4207-4222, 2010.

[23] E. Szmidt and J. Kacprzyk, "A new concept of a similarity measure for intuitionistic fuzzy sets and its use in group decision making," in Modelling Decision For Artificial Intelligence, V. Torra, Y. Narukawa, and S. Miyamoto, Eds., vol. 3558 of Lecture Notes in Artificial Intelligence, pp. 272-282, Springer, 2005.

[24] C. L. Hwang and K. Yoon, Multiple Attribute Decision MakingMethods and Applications, A State-of-the-Art Survey, Springer, New York, NY, USA, 1981.

[25] T. L. Saaty, The Analytic Hierarchy Process, McGraw-Hill, New York, NY, USA, 1980.

[26] M. Zeleny, Multiple Criteria Decision Making, Springer, New York, NY, USA, 1982.

[27] J. Ye, "Multicriteria fuzzy decision-making method using entropy weights-based correlation coefficients of intervalvalued intuitionistic fuzzy sets," Applied Mathematical Modelling, vol. 34, no. 12, pp. 3864-3870, 2010.

[28] Q.-S. Zhang, S. Jiang, B. Jia, and S. Luo, "Some information measures for interval-valued intuitionistic fuzzy sets," Information Sciences, vol. 180, no. 24, pp. 5130-5145, 2010.

[29] A. De Luca and S. Termini, "A definition of a nonprobabilistic entropy in the setting of fuzzy sets theory," Information and Control, vol. 20, no. 4, pp. 301-312, 1972.

[30] I. K. Vlachos and G. D. Sergiadis, "Subsethood, entropy, and cardinality for interval-valued fuzzy sets-An algebraic derivation," Fuzzy Sets and Systems, vol. 158, no. 12, pp. 1384-1396, 2007.

[31] Z.S. Xu, "Methods for aggregating interval-valued intuitionistic fuzzy information and their application to decision making," Control and Decision, vol. 22, no. 2, pp. 215-219, 2007.

[32] Z. S. Xu and J. Chen, "An approach to group decision making based on interval-valued intuitionistic judgment matrices," System Engineering Theory and Practice, vol. 27, no. 4, pp. 126133, 2007.

[33] F. E. Boran, S. Genç, M. Kurt, and D. Akay, "A multi-criteria intuitionistic fuzzy group decision making for supplier selection with TOPSIS method," Expert Systems with Applications, vol. 36, no. 8, pp. 11363-11368, 2009.

[34] T. Y. Chen, H. P. Wang, and Y. Y. Lu, "A multicriteria group decision-making approach based on interval-valued intuitionistic fuzzy sets: a comparative perspective," Expert Systems with Applications, vol. 38, no. 6, pp. 7647-7658, 2011.

[35] S. H. Ha and R. Krishnan, "A hybrid approach to supplier selection for the maintenance of a competitive supply chain," Expert Systems with Applications, vol. 34, no. 2, pp. 1303-1311, 2008.
[36] J. M. Merigo and A. M. Gil-Lafuente, "The induced generalized OWA operator," Information Sciences, vol. 179, no. 6, pp. 729$741,2009$. 


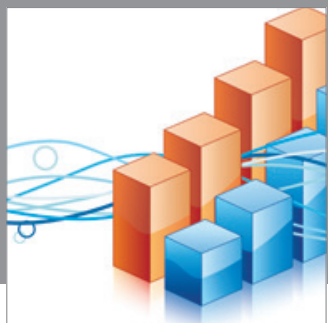

Advances in

Operations Research

mansans

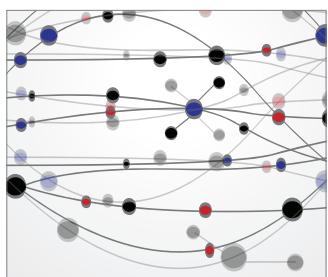

The Scientific World Journal
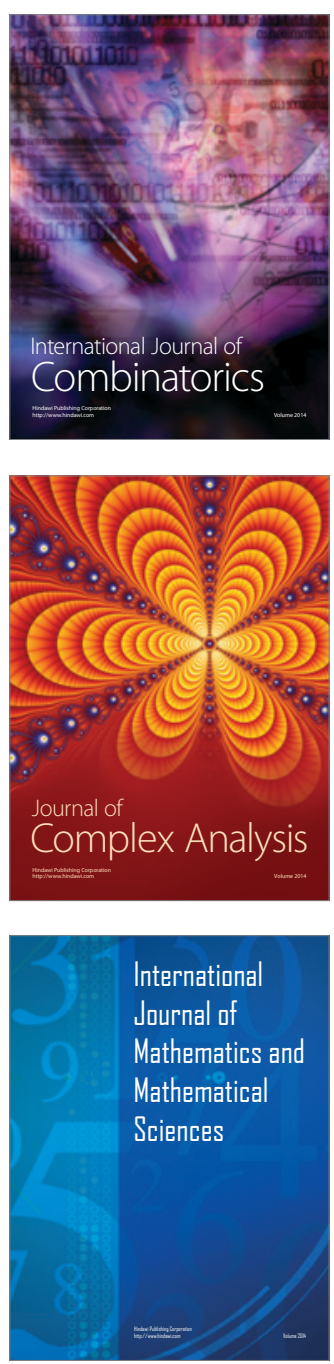
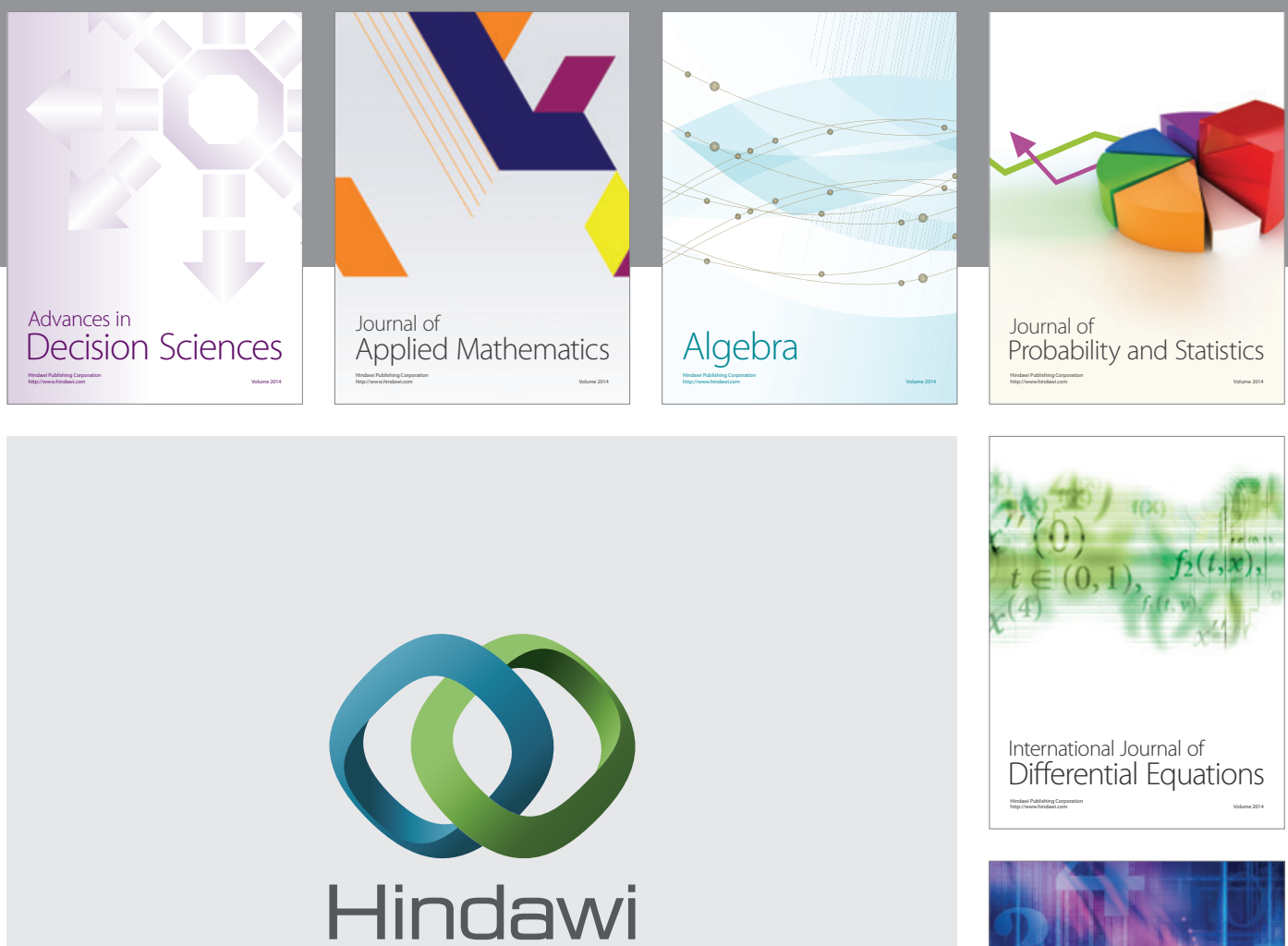

Submit your manuscripts at http://www.hindawi.com
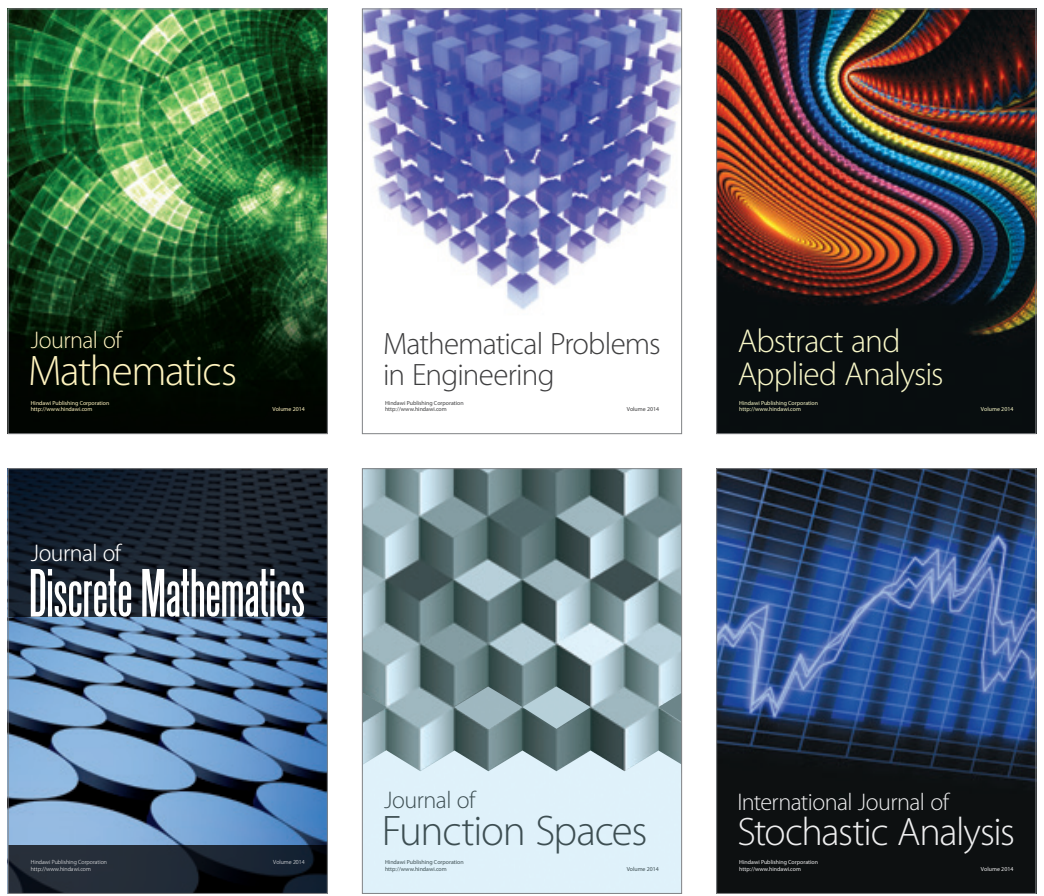

Journal of

Function Spaces

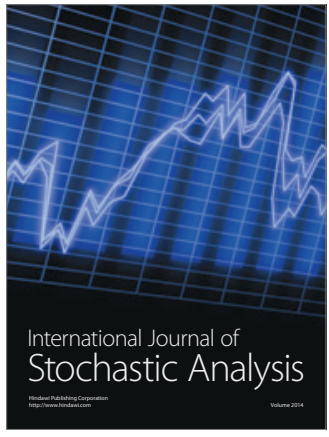

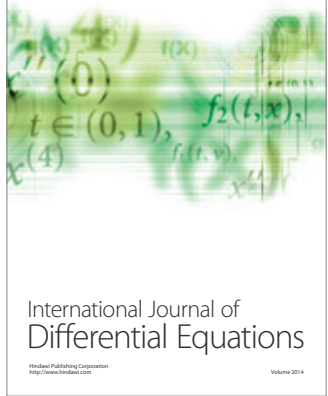
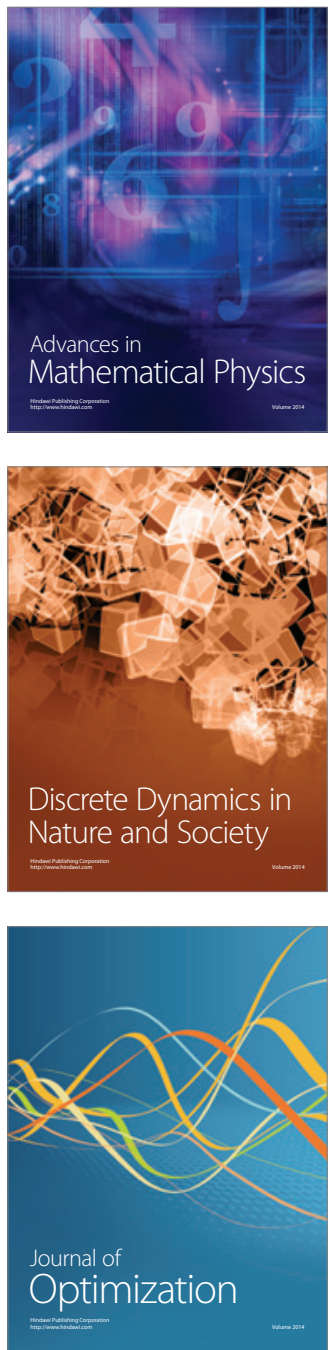